\title{
ECOLOGICAL ADAPTATIONS IN DOUGLAS-FIR (PSEUDOTSUGA MENZIESII var. GLAUCA) POPULATIONS
}

\section{NORTH IDAHO AND NORTH-EAST WASHINGTON}

\author{
GERALD E. REHFELDT \\ Intermountain Forest and Range Experiment Station, Forest Service, U.S. Department of \\ Agriculture, Ogden, Utah 84401, U.S.A. \\ (located at Moscow, Idaho 83843, U.S.A.)
}

Received 26.vi.79

\begin{abstract}
SUMmaRY
Growth, phenology and frost tolerance of seedlings from 50 populations of Douglas-fir (Pseudotsuga menziesii var. glauca) were compared in 12 environments. Statistical analyses of six variables (bud burst, bud set, 3-year height, spring and fall frost injuries, and deviation from regression of 3-year height on 2-year height) showed that populations not only differed in mean performance, but also reacted differently to the environmental gradient. Most of the populationenvironment interaction was attributable to heterogeneous regressions of population means on environmental means. For all variables except growth rate, the variance of heterogeneous regression coefficients was explained by convergence of regression lines to a common point on the environmental gradient. Consequently, mean values for populations were significantly correlated with regression coefficients. Thus, main effects of populations in those single environments that induced the greatest mean differences reflected the interaction.

Multiple regression analyses associated adaptive differentiation of populations with geographic and ecologic characteristics of the seed source. Differentiation was controlled primarily by elevation and secondarily by latitude. Whereas longitude was a minor factor, habitat types accounted for no differentiation beyond that associated with elevation, a factor closely correlated with habitat types. From these results it is recommended that seed for reforestation should not be moved more than 140 m elevation, $1 \cdot 6$ degrees latitude, or $2 \cdot 7$ degrees longitude in northern Idaho and eastern Washington.
\end{abstract}

\section{INTRODUGtion}

Ecological adaptations within northern Rocky Mountain Douglas-fir (Pseudotsuga menziesii var. glauca) differentiate populations from contrasting physiographic and ecological provinces (Rehfeldt, 1979a). The growth potential, phenology, and cold hardiness of seedlings from northern Idaho and eastern Washington differ from those of trees from Montana (Wright et al., 1971; Rehfeldt, 1979a, b). Also, seedlings from relatively cold environments differ from seedlings representing warm environments (Rehfeldt, $1979 a, b, c)$. Nevertheless, physiographic and ecologic provinces account for only a portion of the genetic variance in numerous traits (Rehfeldt, 1979a). Considerable genetic diversity exists among populations within provinces and within populations (Rehfeldt, 1978, 1979a).

Adaptive variation is basic to the delineation of seed zones and development of seed transfer rules. According to Campbell and Sorensen (1978), the need for seed zones in artificial afforestation was recognized long ago. In seed zoning, forest lands are stratified into units within which interactions between genotype and environment approach zero. Estimates of genetic 
components of variance within zones allow prediction of the genetic gains possible when maladaptation is minimized.

The present study is one of a series on the ecological genetics of the Rocky Mountain variety of Douglas-fir. The study was designed to assess variation in growth potential and in the periodicity of shoot elongation among populations from a single physiographic province: northern Idaho and northeastern Washington. The current data are combined with those involving variation in patterns of 1st-year elongation (Rehfeldt, 1979b) and variation in cold acclimation (Rehfeldt, 1979c) to develop seed zones and seed transfer rules from patterns of adaptive variation.

\section{Methods}

In the selection of 50 populations (fig. 1) to study genetic differentiation, an attempt was made to reduce confounding of latitudes, longitudes, elevations, and habitat types represented by the populations. A lack of correlation among physical characteristics of the seed sources reduces possibilities of spurious correlations between genetic variation and geographic, physiographic or ecologic criteria. Nevertheless, statistically significant ( 1 per cent

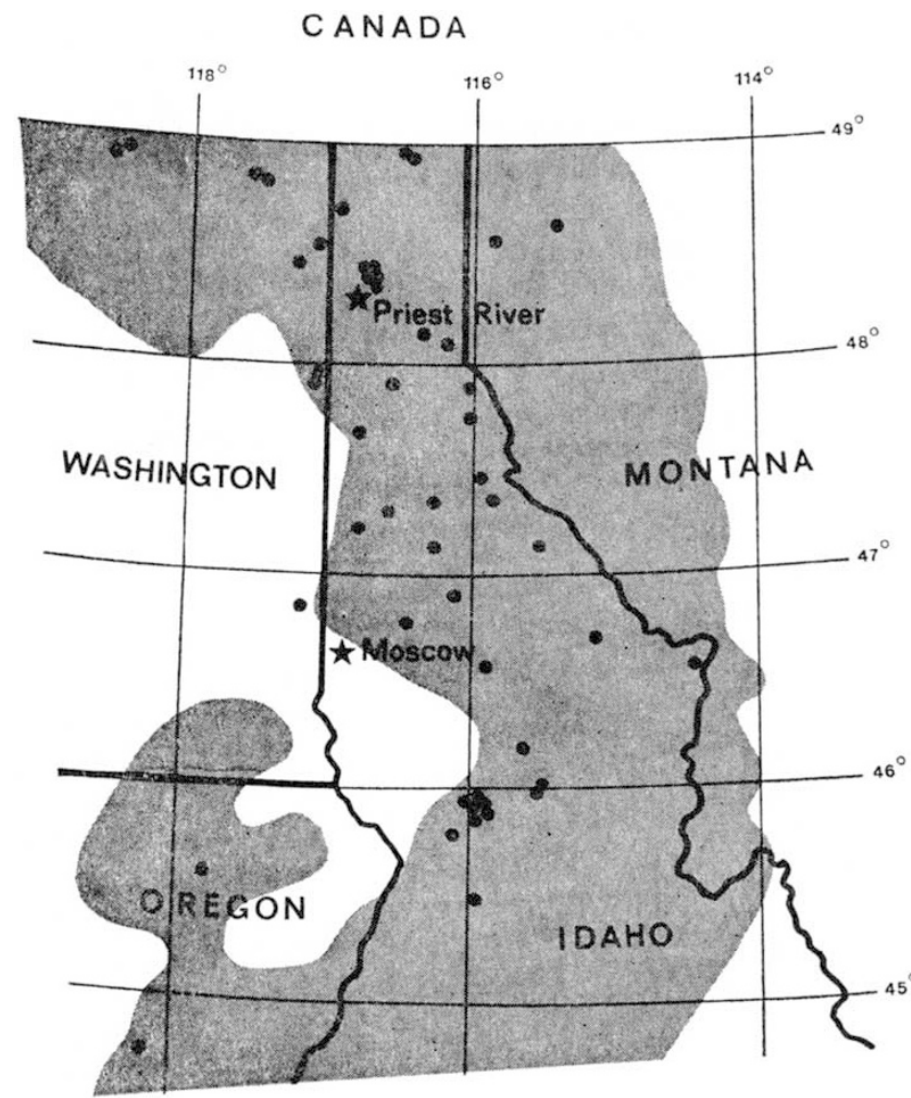

FIG. 1.-Location of populations. Shaded area represents a general distribution of forested lands. 
level) associations between latitude and longitude $(r=0.34)$ and between elevation and habitat type $\left(R^{2}=0 \cdot 25\right)$ were represented by the populations chosen. While the former correlation arises largely from the distribution of forested lands within the region of study (fig. l), the latter is derived from a general altitudinal distribution of habitat types, recurring climax plant communities (Daubenmire and Daubenmire, 1968). Habitat types were classified according to the five major series common in northern Idaho and eastern Washington, and are listed according to a general ascending altitudinal distribution: Pseudotsuga menziesii, Abies grandis, Thuja occidentalis, Tsuga heterophylla, and Abies lasiocarpa (Daubenmire and Daubenmire, 1968).

Cones that had received natural wind pollinations were collected from each population in years when cone production was generally high. At least 10 trees were represented in collections for each population. Seedlings were grown for 1 year in plastic tubes $\left(65 \mathrm{~cm}^{3}\right)$ in a shadehouse at Moscow, Idaho. One-year-old seedlings were transplanted into 12 contrasting environments (table 1). Twelve seedlings were planted in row plots for each of two replications in each environment. Rows were separated by $10 \mathrm{~cm} ; 8 \mathrm{~cm}$ separated seedlings within rows.

At Moscow, elevation $700 \mathrm{~m}$, eight environments were created by altering natural prairie conditions with combinations of shade, soil mix, and watering regimes (table 1). Moist levels of soil moisture were maintained with weekly irrigations; dry levels received natural precipitation. Shade cloth was suspended $1 \mathrm{~m}$ above shaded environments. Four plantings were established at the Priest River Experimental Forest, located $190 \mathrm{~km}$ north of Moscow. Two of these plantings were established in a nursery (670 m elevation) and two at North Ridge, a subalpine environment at $1500 \mathrm{~m}$ elevation. Although the residual soil was used in the last two plantings, rocks, roots, and competing vegetation had been removed before tilling. All plantings at Priest River received natural precipitation.

Phenology, growth, and frost tolerance of seedlings were assessed from the following scores and measurements obtained for each population in all replications :

(1) Bud burst: the day after lst April during the third growing season that 50 per cent of the seedlings had burst terminal buds.

(2) Bud set: the week during the third growing season by which 50 per cent of the seedlings had set terminal buds.

(3) Height: average seedling height after 3 years of growth.

(4) Growth rate: average deviation from regression of 3-year height on 2-year height; an index to the rate of growth from a constant height at age 2 .

(5) Spring frost injury: proportion of seedlings injured by spring frosts during the third growing season.

(6) Fall frost injury: proportion of seedlings injured by fall frosts during the third growing season.

The response of seedlings from individual populations to the 12 environments was assessed by joint regression analyses (Perkins and Jinks, 1968). The joint regression analysis, a form of the analysis of variance, allows detailed examination of genotype-environment interactions (Freeman, 1973). A regression coefficient, computed by regressing mean values of genotypes from several environments on environmental means, can be used to describe 
GERALD E. REHFELDT

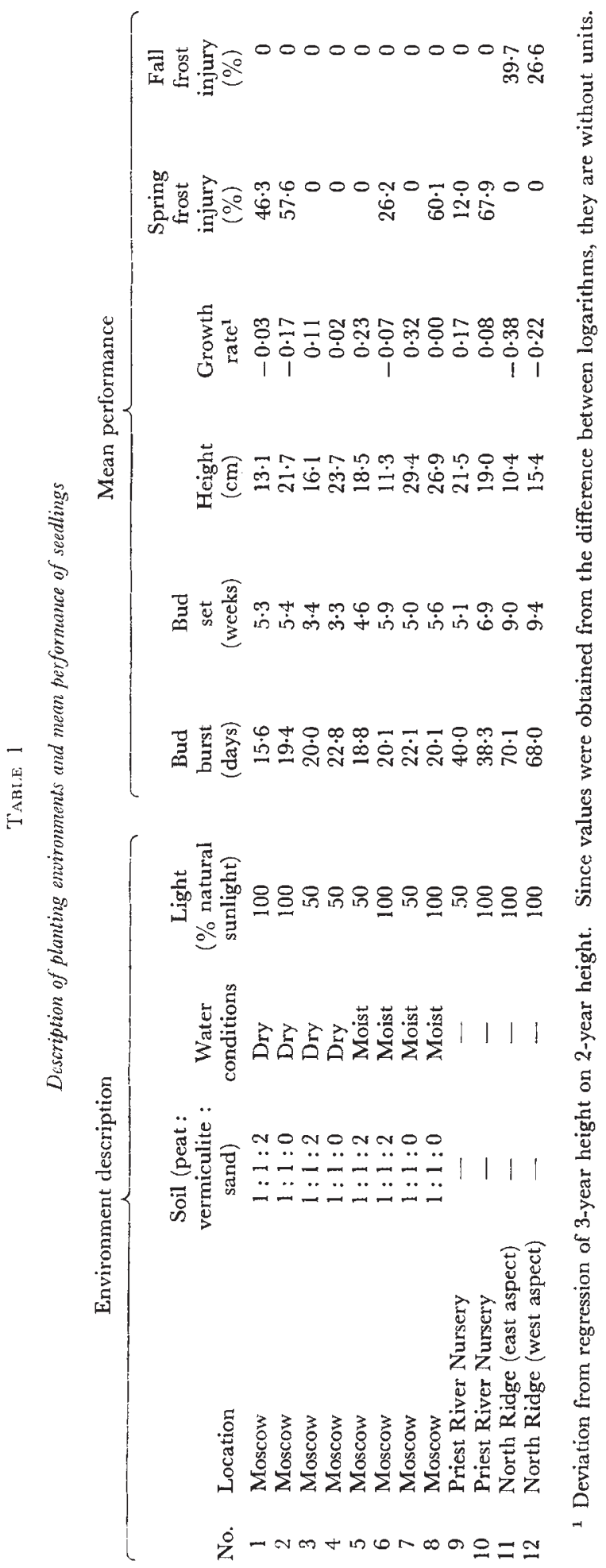


genotypic response to an environmental gradient (Yates and Cochran, 1938; Finlay and Wilkinson, 1963). The joint regression analysis can then be used to measure the portion of the variance for genotype-environment interactions that is due to heterogeneity of regression coefficients among genotypes (Eagles et al., 1977). Thus, the total genotype-environment interaction is partitioned into components due to regression and deviation from regression. Moreover, the tendency of regression lines to converge at a single point on the environmental gradient can also be tested (Eagles et al., 1977).

Joint regression analyses were used for only bud burst, bud set, height, and growth rate; injuries from frost occurred in too few environments for practical application of regression analyses. Measurements of height were transformed to logarithms because variances were proportional to the square of mean values (Steel and Torrie, 1960). The joint regression analyses used the model of random effects presented by Perkins and Jinks (1968) and illustrated by Eagles et al. (1977):

$$
Y_{i j k}=\mu+p_{i}+e_{j}+r_{j k}+\beta_{i} e_{j}+\delta_{i j}+d_{i j k}
$$

where $Y_{i j k}$ is the performance of population $i$ in replicate $k$ of environment $j$, $\mu$ is the overall mean, $p_{i}$ is the contribution of population $i, e_{j}$ is the contribution of environment $j, r_{j k}$ is the contribution of replicate $k$ in environment $j, \beta_{i}$ is the linear regression coefficient for population $i, \delta_{i j}$ is the deviation from regression, and $d_{i j k}$ is the residual variation.

As described by Eagles et al. (1977), the sum of squares for heterogeneity of regression coefficients was partitioned into components for convergence and non-convergence according to the relationship of Mandel (1961):

$$
s=r^{2} H^{2}
$$

where $s$ is the sum of squares for convergence, $r$ is the simple correlation between the mean performance and the regression coefficient, and $H^{2}$ is the sum of squares due to heterogeneity of regressions.

Analyses of variance for frost injuries were made from a model of random effects:

$$
Y_{i j k}=\mu+p_{i}+e_{j}+r_{j k}+g_{i j}+d_{i j k}
$$

for which symbols are defined above except for $g_{i j}$, the effect of the interaction of population $i$ in environment $j$.

Variation among populations was related to geographic and ecologic criteria of the seed source with the model:

where:

$$
Y_{i}=b_{0}+b_{1} X_{i 1}+b_{2} X_{i 2} \ldots+b_{7} X_{i 7}
$$

$Y_{i}=$ performance of population $i$.

$X_{i 1}$ to $X_{i 4}=$ constant terms (values of zero or one) that code the Pseudotsuga menziesii $\left(X_{1}\right)$, Abies grandis $\left(X_{2}\right)$, Thuja occidentalis $\left(X_{3}\right)$, or Abies lasiocarpa $\left(X_{4}\right)$ habitat type for population $i$.

$X_{i 5}=$ degrees latitude at the origin of population $i$.

$X_{i 6}=$ degrees longitude at the origin of population $i$.

$X_{i 7}=$ metres elevation at the origin of population $i$.

Under this model, effects of the Tsuga heterophylla series of habitat types are included within the intercept $\left(b_{0}\right)$. Consequently, the regression coefficients for constant terms $\left(b_{1}\right.$ to $\left.b_{4}\right)$ reflect deviations from the mean value 
for seedlings from the Tsuga heterophylla series of habitat types. For all multiple regression equations, residuals from regression were examined visually in relation to predicted and observed variables to ensure that error variances were homogeneous and that no evidence existed for lack of fit of data to the regression equation (Draper and Smith, 1966). Results of multiple regression analyses provided bases for delineation of seed zones and development of seed transfer rules.

\section{RESUlts}

The 12 environments exerted considerable influence on growth, phenology, and frost injury to seedlings (tables 1 and 2). Compared to seedlings at Moscow, bud burst was delayed about 3 weeks at the Priest River nursery and about 7 weeks at North Ridge. In conjunction with delayed bud burst, seedlings at North Ridge escaped the spring frost damage that occurred in all other environments not protected by shade cloth. Although bud set occurred over an interval of 6 weeks, the effects of delayed bud set at North Ridge are the most apparent; succulent tissues were exposed to frosts in late September. In fact, some seedlings at North Ridge incurred frost injuries before terminal buds were set.

Effects of environment on seedling height and on growth rate are readily interpretable from the amount of frost injury and from the imposed environmental conditions. For instance, a negative value for growth rate characterised the average seedling in those Moscow environments in which spring frost damage occurred. The small stature and negative values for growth rate of seedlings at North Ridge generally reflected a short cool growing season and fall frost injuries. Thus, even if all seedlings had been of equal height at age 2, those at North Ridge would still be the smallest at age 3. Conversely, a Moscow environment of abundant moisture, partial shade, and a peat and vermiculite substrate produced the tallest and fastest growing seedlings.

In addition to illustrating strong main effects of populations, the joint regression analyses showed that significant interactions between populations and environments were significantly influenced by heterogeneous regression coefficients among populations (table 2). Deviations from regression also were significant for three of the four variables subjected to joint analyses. Yet, mean squares for deviations from regression were only slightly larger than residual mean squares; statistical significance most likely was induced by a large number of degrees of freedom rather than by a poor fit to the regression model (fig. 2).

Variance of heterogeneous regressions for bud burst, bud set, and height resulted entirely from convergence of regression lines (table 2). Thus, as illustrated in fig. 2, regression lines for bud burst, bud set, and height tended to converge at a single point on the environmental gradient and radiated away from that point with varying slopes. As pointed out by Eagles $e$ al. (1977) and observed by several others (Eberhart and Russell, 1966; Perkins. and Jinks, 1968; Morgenstern and Teich, 1969; Fatunla and Frey, 1974), convergence occurs when mean values across all environments are correlated with the regression coefficients. For both convergence and non-convergence to be significant for growth rate simply reflects a weaker relationship between means and regression coefficients than for the other variables. Consequently, 

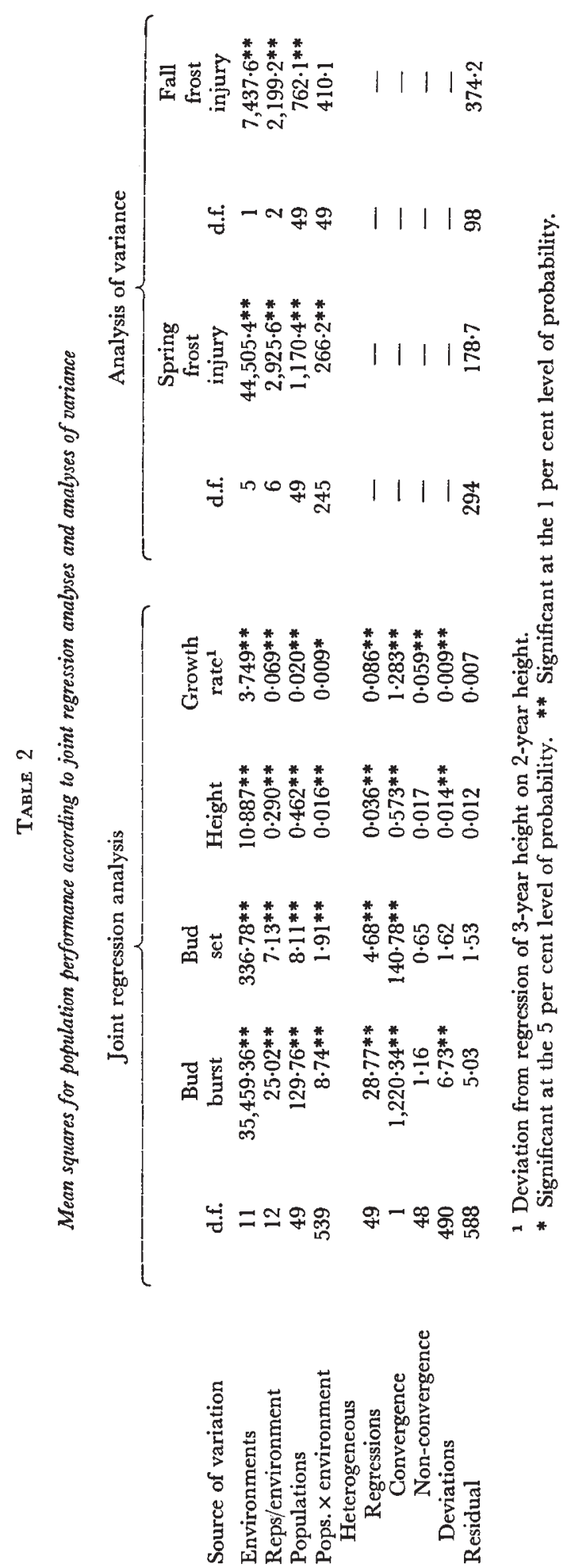
significant correlations ( 1 per cent level) between population means and regression coefficients are evident for all variables (fig. 3 ).

Although data on frost injuries were not subjected to joint regression analyses, results of such an analysis are readily envisioned. Regardless of the analyses of variance, population-environment interactions existed simply because differential damage was attributed to populations in some environments, but no such damage occurred in other environments. Consequently, convergence occurs at zero injury on the environmental scale and regression lines radiate from zero at varying slopes toward points of maximal frost injuries.

The analyses presented previously provided two statistics for each variable that were suitable for relating population performance to geographic and ecologic conditions of the seed source: mean values for populations across all environments, and regression coefficients of population means on environmental means. Both statistics were used as dependent variables in multiple regression analyses. However, because of the strong relationships between means and regression coefficients, results of analyses for bud burst and bud
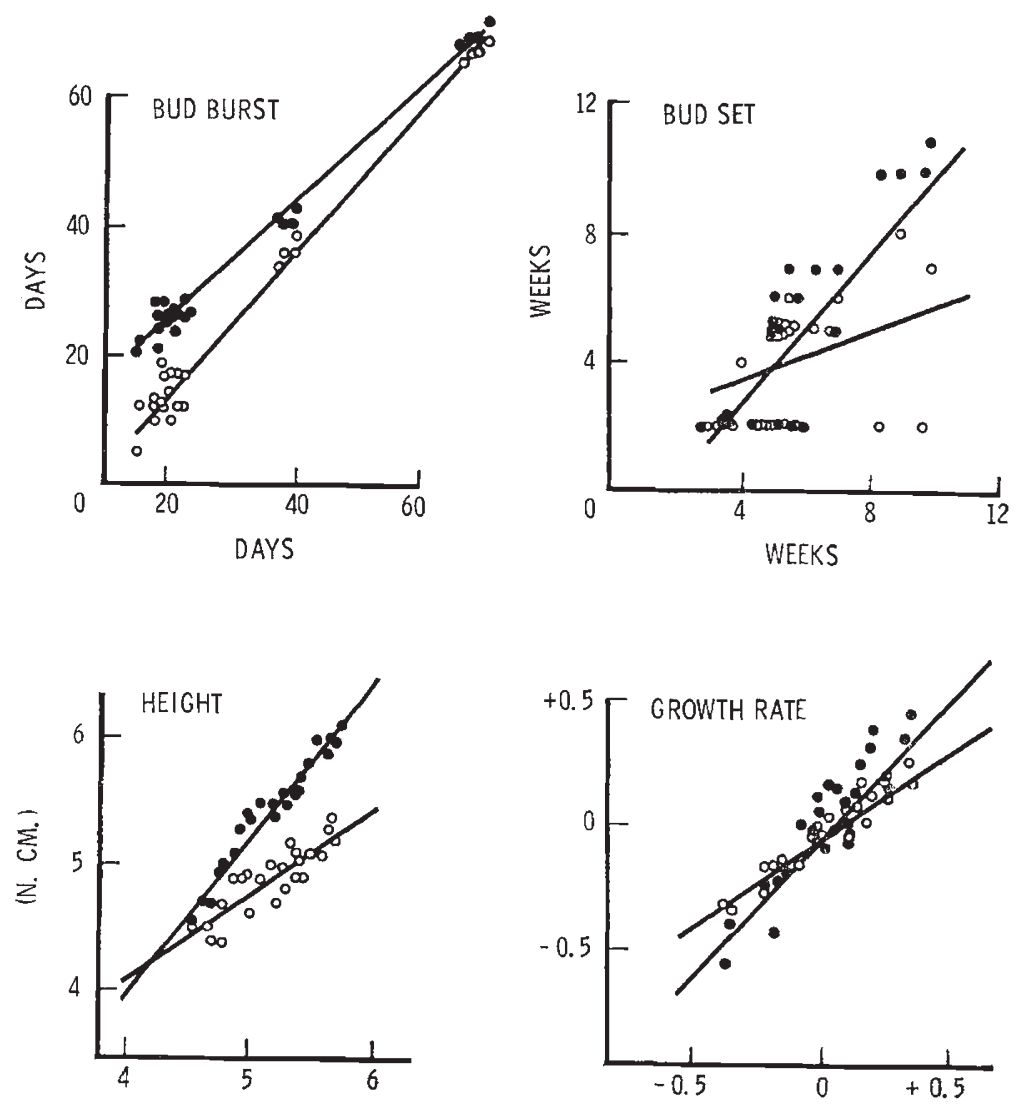

(N. CM.)

FIG. 2.-Regression of population performance (ordinant) on environmental means (abscissa) illustrated by populations of maximum contrast for each variable. Solid or open dots show dispersion of observed values for each replication about regression lines. 
set were essentially the same regardless of whether dependent variables involved regression coefficients or means. But, means for height and for growth rate provided a much better fit to multiple regression models than did regression coefficients; in fact, values of $R^{2}$ for height and growth rate, respectively, were altered from non-significant values of 0.22 and 0.15 to significant values ( 1 per cent level) of 0.51 and 0.40 when mean values were substituted for regression coefficients. Consequently, in the results of multiple regression analyses that follow, population means were used as dependent variables.

Multiple regression analyses were first made with data from all 50 populations. However, visual assessment of relationships among predicted and observed values showed that the three populations of greatest longitude (fig. 1) drove relationships between longitude and population performance that were not evident for the remaining 47 populations. For instance, the simple correlation between longitude and mean week of bud set was reduced
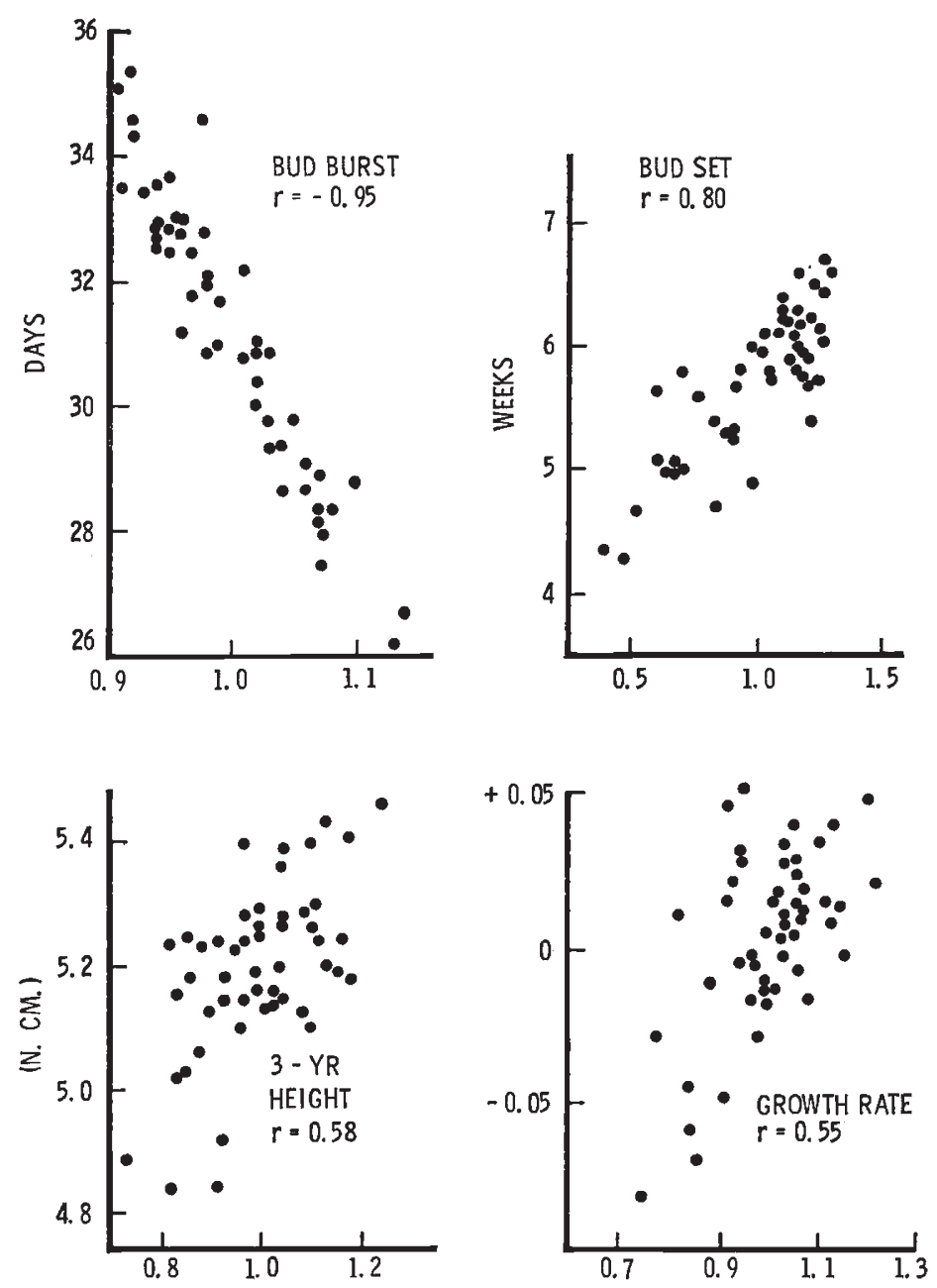

FIG. 3.-Relationships between mean values (ordinate) and regression coefficients (abscissa). $43 / 3-\mathrm{G}$ 
from a significant ( 5 per cent level) value of -0.35 to 0.01 after the three populations were eliminated. Consequently, the three populations of greatest longitude seemed to represent provinces that differ from the northern Idaho and eastern Washington province like the Idaho and Washington province differs from those of western Montana (Rehfeldt, 1979a) and

TABLE 3

Regression statistics for multiple regression models for relating mean performance of 47 populations to geographic and ecologic conditions of the seed source

\begin{tabular}{|c|c|c|c|c|c|c|c|}
\hline \multirow[b]{2}{*}{$\begin{array}{l}\text { Independent } \\
\text { variable }\end{array}$} & \multirow[b]{2}{*}{$\begin{array}{l}\text { Regression } \\
\text { statistic }\end{array}$} & \multicolumn{6}{|c|}{ Variable } \\
\hline & & $\begin{array}{l}\text { Bud } \\
\text { burst }\end{array}$ & $\begin{array}{c}\text { Bud } \\
\text { set }\end{array}$ & Height & $\begin{array}{l}\text { Growth } \\
\text { rate }^{1}\end{array}$ & $\begin{array}{l}\text { Spring } \\
\text { frost } \\
\text { injury }\end{array}$ & $\begin{array}{c}\text { Fall } \\
\text { frost } \\
\text { injury }\end{array}$ \\
\hline \multicolumn{8}{|l|}{ Habitat series: } \\
\hline P. menziesii & $b_{1}$ & -1.874 & $-0 \cdot 316$ & $-0 \cdot 0200$ & $-0 \cdot 00114$ & -0.327 & -0.597 \\
\hline A. grandis & $b_{2}$ & $-0 \cdot 167$ & $-0 \cdot 081$ & 0.0094 & 0.00769 & 1.709 & $3 \cdot 181$ \\
\hline T. occidentalis & $b_{3}$ & -1.097 & $0 \cdot 006$ & 0.0470 & 0.00299 & 2.498 & $9 \cdot 765$ \\
\hline A. lasiocarpa & $b_{4}$ & 0.747 & $0 \cdot 203$ & 0.0541 & 0.00039 & $7 \cdot 274$ & $7 \cdot 745$ \\
\hline Latitude & $b_{5}$ & $0 \cdot 089$ & $-0 \cdot 101$ & -0.0258 & 0.00131 & -1.838 & $-3 \cdot 253$ \\
\hline Longitude & $b_{6}$ & $-0 \cdot 400$ & -0.019 & 0.0117 & 0.00684 & -0.417 & $3 \cdot 281$ \\
\hline \multirow[t]{4}{*}{ Elevation } & $b_{7}$ & $0 \cdot 004$ & $-0 \cdot 001$ & -0.0003 & -0.00005 & $-0 \cdot 019$ & -0.032 \\
\hline & $b_{0}$ & $29 \cdot 795$ & $8 \cdot 219$ & $5 \cdot 7220$ & $1 \cdot 27479$ & $82 \cdot 076$ & $68 \cdot 952$ \\
\hline & $R^{2}$ & $0 \cdot 29 *$ & $0.31 *$ & $0.42 * *$ & $0 \cdot 31 *$ & $0 \cdot 22$ & $0.36 * *$ \\
\hline & $s_{y \cdot x}$ & $2 \cdot 162$ & $0 \cdot 445$ & 0.095 & 0.022 & 7.901 & $11 \cdot 35$ \\
\hline
\end{tabular}

1 Deviation from regression of 3-year height on 2-year height.

* Statistical significance at the 0.05 level of probability. ** Statistical significance at the 0.01 level of probability.

TABLE 4

Standardized partial regression coefficients $\left(\mathrm{b}^{\prime}\right)$ for the quantitative independent variables represented in multiple regressions of population performance on environmental characteristics of the seed source

\begin{tabular}{lrccccc} 
& \multicolumn{9}{c}{ Variable } \\
& $\begin{array}{c}\text { Bud } \\
\text { burst }\end{array}$ & $\begin{array}{c}\text { Bud } \\
\text { set }\end{array}$ & Height & $\begin{array}{c}\text { Growth } \\
\text { rate }^{1}\end{array}$ & $\begin{array}{c}\text { Spring } \\
\text { frost } \\
\text { injury }\end{array}$ & $\begin{array}{c}\text { Fall } \\
\text { frost } \\
\text { injury }\end{array}$ \\
Latitude $\left(X_{5}\right)$ & 0.04 & -0.22 & -0.28 & 0.08 & -0.24 & -0.27 \\
Longitude $\left(X_{6}\right)$ & -0.12 & -0.03 & 0.07 & 0.19 & -0.03 & 0.17 \\
Elevation $\left(X_{7}\right)$ & 0.37 & -0.59 & -0.67 & -0.44 & -0.52 & -0.54
\end{tabular}

1 Deviation from regression of 3-year height on 2-year height.

southern Idaho (Wright et al., 1971). Therefore, results of multiple regression analyses (table 3 ) are based on mean values for 47 populations, even though values of $R^{2}$ were reduced by about $0 \cdot 10$ when the three populations were eliminated.

Effects of the continuous independent variables of latitude, longitude, and elevation, on variation among populations can be assessed from standardized partial regression coefficients which indicate the relative influence of independent variables in determining the dependent variable. These coefficients (table 4) show that elevation of the seed source dominates the determination of all variables; latitude is of secondary importance. 
The constant terms for the four series of habitat types $\left(b_{1}\right.$ to $\left.b_{4}\right)$ in the multiple regression model are deviations from the mean value for the habitat type ( $T$ suga heterophylla) not represented by a constant term. That none of the constant terms is significantly different from zero shows that mean values for all habitat types did not differ from the mean value of seedlings from the Tsuga series. However, for all but two variables, effects of the Pseudotsuga and Abies lasiocarpa habitats contrasted the most. Moreover, previous research (Rehfeldt, 1979a, $b$ ) suggested that seedlings from the relatively cold Abies lasiocarpa habitat types are genetically differentiated from seedlings from other habitat types. However, for the populations included in multiple regression analyses, the occurrence of habitat types was related to elevation

TABLE 5

Simple correlation coefficients relating mean performance of populations

\begin{tabular}{|c|c|c|c|c|c|c|}
\hline & $\begin{array}{c}\text { Bud } \\
\text { burst }\end{array}$ & $\begin{array}{c}\text { Bud } \\
\text { set }\end{array}$ & Height & $\begin{array}{l}\text { Growth } \\
\text { rate }^{1}\end{array}$ & $\begin{array}{l}\text { Spring } \\
\text { frost } \\
\text { injury }\end{array}$ & $\begin{array}{l}\text { Fall } \\
\text { frost } \\
\text { injury }\end{array}$ \\
\hline Bud burst & - & -0.07 & $-0.27 *$ & $-0.35 * *$ & 0.03 & -0.21 \\
\hline Bud set & - & - & $0 \cdot 86 * *$ & 0.6 & 4** & $0.75 * *$ \\
\hline Height & - & - & - & $0.68 * *$ & $0.79 * *$ & $0.70 * *$ \\
\hline Growth rate & - & - & - & - & $0.51 * *$ & $0.48 * *$ \\
\hline Spring frost injury & - & - & - & - & - & $0.57 * *$ \\
\hline injury :2 & & & & & & \\
\hline Phase I & -0.20 & $0.59 * *$ & $0.69 * *$ & $0.34 * *$ & $0.55 * *$ & $0 \cdot 67 * *$ \\
\hline Phase II & -0.15 & -0.28 & -0.27 & -0.25 & $-0.33^{* *}$ & $-0 \cdot 12$ \\
\hline $\begin{array}{l}\text { Proportion trees } \\
\text { with one growth } \\
\text { period }\end{array}$ & 0.28 & $-0.69 * *$ & $-0.78^{* *}$ & $-0.53^{* *}$ & $-0.59 * *$ & $-0.63^{* *}$ \\
\hline
\end{tabular}

1 Deviation from regression of 3-year height on 2-year height.

${ }^{2}$ From Rehfeldt, $1979 c$.

3 From Rehfeldt, $1979 b$.

* Statistical significance at the 5 per cent level of probability.

** Statistical significance at the 1 per cent level of probability.

$\left(R^{2}=0.28^{*}\right)$; and for the region in general, Abies lasiocarpa habitat types tend to occur at high elevations while those of the Pseudotsuga habitat types tend to be at low elevations (Daubenmire and Daubenmire, 1968). Consequently, mean differences associated with habitat types may simply reflect indirect effects of elevation that are mediated through an intercorrelation between elevation and habitat type. The lack of significant differences among regression coefficients $b_{1}$ to $b_{4}$ implies that habitat types account for little variation in addition to that associated with elevation; a conclusion similar to that of Rehfeldt (1979c) for Pseudotsuga menziesii var. glauca and by Campbell and Franklin (1979) for P. m. var. menziesii.

Many of the variables measured in the present and previous studies seem to reflect a highly intercorrelated network of traits (table 5). Population means for growth, frost injuries, and bud set are highly correlated. These same variables are strongly related to freezing injuries (Rehfeldt, 1979c) during early autumnal stages of cold acclimation (Phase I). Furthermore, the proportion of seedlings in each population that expressed a single period of growth during the first growing season (Rehfeldt, 1979b) also seems to be an integral part of an intercorrelated network. Only bud burst and freezing 
injury during deep winter dormancy (Phase II) are poorly correlated with most variables.

\section{Discussion}

The results illustrate conditions for which regression techniques are ideal for the selection of genotypes that are the best adapted and the most productive for a particular segment of an environmental gradient. Most of the genotype-environment interaction was explained by heterogeneity of regressions; convergence determined heterogeneity for all but one variable, and convergence occurred within the range of environments tested (Perkins and Jinks, 1968; Eagles et al., 1977). However, in the present paper regression techniques were not used for the selection of genotypes but were used for comparing the response of populations to an environmental gradient. For two variables, bud burst and bud set, convergence of regression lines was so strong that mean values were highly correlated with regression coefficients; variance among population means explained nearly all of the variance of heterogeneous regressions. Moreover, variation among populations for spring and fall frost damage was interpreted as was variation for bud burst.

Mean values of height and growth rate were also significantly correlated with regression coefficients. However, in comparison to regression coefficients, population means expressed higher intercorrelations among variables and a better fit to multiple regression models. Evidently the estimation of regressions in the joint analysis masked population variation in height and growth rate that was vital for assessing population differentiation. It seems that population means for variables that express environmental adaptations fully indexed the response of populations to the environmental gradient. For all variables assessed in this study, main effects of populations in those single environments that induced the most variation among populations also included population-environment interactions.

Thus, this study, designed to assess interactions between populations and environments, could have been accomplished without loss of information with tests in only two environments. Maximum variation among populations in bud set occurred at North Ridge; that for bud burst, height, and growth rate occurred in environment 7 at Moscow (table 1). Even though spring and fall frost damage was observed in specific environments, studies of frost hardiness are more feasible with laboratory tests than with field tests which must rely on a fortuitous sequence of weather cycles (Levitt, 1972).

Differentiation of populations was evidenced by concomitant variation in several variables. Strong intercorrelations seemed to reflect a network of closely related traits. Consequently, relative effects for independent variables in multiple regression models were consistent for the determination of all variables except bud burst; most noticeable was the strong effect of elevation. Thus, an intercorrelated network of traits seems to represent adaptation of populations to the cold, a relationship that was earlier interpreted as reflecting differentiation of populations from Abies lasiocarpa habitat types from those of other habitats (Rehfeldt $1979 a, b, c)$. Thus, in comparison to seedlings from low elevations, those from relatively cold subalpine environments at high elevations are characterized by a single flush during the first growing season, delayed bud burst, early bud set, small stature, low growth rate, and rapid rates of cold acclimation. All of these characters seem to represent adaptation of the period of shoot elongation to the cold. 
The physiologic mechanism for adaptation of the period of shoot elongation to the cold is readily envisioned from patterns of shoot elongation in juvenile Douglas-fir. While multiple flushes are common in juvenile trees, the number and extent of flushes is dependent on provenance (Irgens-Moller, 1968; Rehfeldt, 1979b). Although the number of flushes was not scored in the present study, those trees that flushed twice were initiating their second flush at North Ridge when bud set was occurring elsewhere. Fall frost injury at North Ridge seemed related to the extent of the second flush. Thus, for juvenile trees, genetic attunement of shoot elongation to the environment seems expressed in the control of tendencies for multiple flushes. Quite surprisingly, adaptive differences among populations in the periodicity of shoot elongation can be recognised during the first season of growth by the proportion of seedlings that flush only once.

Adaptive differentiation of populations forms bases for delineation of seed zones and for development of seed transfer rules. Results of the joint

TABLE 6

Geographic distances associated with mean differences among seed sources that correspond to a significance level of 80 per cent.

\begin{tabular}{|c|c|c|c|c|c|c|}
\hline & & & & ble & & \\
\hline & $\begin{array}{l}\text { Bud } \\
\text { burst }\end{array}$ & $\begin{array}{c}\text { Bud } \\
\text { set }\end{array}$ & Height & $\begin{array}{c}\text { Growth } \\
\text { rate }\end{array}$ & $\begin{array}{l}\text { Spring } \\
\text { frost } \\
\text { injury }\end{array}$ & $\begin{array}{c}\text { Fall } \\
\text { frost } \\
\text { injury }\end{array}$ \\
\hline Latitude (degrees) & $12 \cdot 2$ & $5 \cdot 1$ & $1 \cdot 6$ & $26 \cdot 2$ & $4 \cdot 7$ & $5 \cdot 7$ \\
\hline Longitude (degrees) & 2.7 & $26 \cdot 2$ & $4: 0$ & $5 \cdot 0$ & 20.7 & $5 \cdot 7$ \\
\hline Elevation (metres) & 274 & 386 & 136 & 708 & 447 & 587 \\
\hline
\end{tabular}

1 Deviation from regression of 3-year height on 2-year height.

regression analyses allowed calculation of mean differences among populations that were associated with least significant differences $(l s d)$ at various levels of probability (Steel and Torrie, 1960). Multiple regression models were used to calculate the distances in longitude, latitude, and elevation required to alter the dependent variables an amount equal to the mean differences derived above for various levels of statistical significance.

Geographic distances associated with mean differences among populations that were significant at $l s d_{0,8}$ are given in table 6 . Distances associated with a relatively low level of probability $\left(l s d_{0.8}\right)$ are presented because the primary objective in seed zoning is to provide seedlings adapted to the environments in which they are planted. Type II errors, acceptance of no difference among populations when differences actually exist (Steel and Torrie, 1960), are to be avoided. Geographic distances associated with $l s d_{0.5}$ are approximately one-half those presented in table 6 ; distances for $l s d_{0.95}$ are greater by a factor of $1 \cdot 5$. Consequently, the distances presented in table 6 seem suitably conservative for avoiding Type II errors but sufficiently large to have practical application.

Table 6 implies that seed zones should be no larger than $140 \mathrm{~m}$ elevation, 1.6 degrees latitude or 2.7 degrees longitude. Units of this size are also compatible with variation in cold hardiness (Rehfeldt, 1979c) and variation in patterns of 1st-year elongation (Rehfeldt, 1979b). However, previous reports also concluded that relatively cold Abies lasiocarpa habitat types 
represent an additional zone of differentiation (Rehfeldt, 1979a, $b$ ). But the current analyses like those of cold acclimation (Rehfeldt, 1979c) show that habitat types account for no more variance than can be attributed to elevation alone. Consequently, there is no need for Abies lasiocarpa habitat types to form a separate seed zone.

Relatively broad seed zones and liberal seed transfer rules seem compatible with the system of genetic variability displayed by Douglas-fir in the region of study. Genetic adaptation of populations occurs along environmental gradients. However, less than half of the genetic variance among populations for the present study and previous (Rehfeldt, 1979b, c) studies could be explained by environmental gradients. Some of the unexplained variance results from random patterns of differentiation that occur within single drainages (Rehfeldt, 1974). And as much genetic variation exists among trees within populations as between populations within the region of study (Rehfeldt, 1979a). Genetic variances within families are high, largely because individual trees are highly heterozygous (Rehfeldt, 1978).

The system of genetic variability displayed by Douglas-fir of the northern Rocky Mountains includes free genetic variability at all levels of organization. This system provides for environmental adaptations while retaining flexibility and resiliency for evolution. A strategy of tree improvement that is consistent with the natural genetic system should include relatively broad seed zones and liberal seed transfer rules. In fact, because large amounts of adaptive variation are anticipated within zones, delineation of zonal boundaries may be influenced by economic factors, such as the costs of seed collection, nursery operation, and plantation establishment.

Studies on the ecological genetics of northern Rocky Mountain Douglasfir will continue. Present results will be compared with adaptive differentiation of populations in western Montana and southern Idaho, two provinces where Douglas-fir populations are genetically differentiated from those of northern Idaho and eastern Washington (Wright et al., 1971; Rehfeldt, $1979 a, c)$.

\section{REFERENCES}

CAMPBEll, R. K., AND FRANKLiN, J. F. 1979. Seed zone classification by habitat type or elevation-a comparison. For. Sci. (in Press).

GAMPBELL, R. K., AND SORENSEN, F. C. 1978. Effect of test environment on expression of clines and on delimitation of seed zones in Douglas-fir. Theoret. Appl. Genet., 51, 233-246.

DAUBENMiRE, R., AND DAUBENMiRe, J. B. 1968. Forest vegetation of eastern Washington and northern Idaho. Wash. Agric. Exp. Stn. Tech. Bull., 60, 104 pp.

Draper, N. R., AND smith, H. 1966. Applied Regression Analysis, 407 pp. John Wiley and Sons, Inc., New York.

EAGLES, H. A., PINZ, P. N., and FREY, K. J. 1977. Selection of superior cultivars of oats by using regression coefficients. Crop Sci., 17, 101-105.

EBERHART, s. A., AND RUSSELL, W. A. 1966. Stability parameters for comparing varieties. Crop Sci., 6, 36-40.

FATUNLA, T., AND FREY, K. J. 1974. Stability indexes of radiated and non-radiated oat genotypes propagated in bulk populations. Crop Sci., 14, 719-724.

FinlAY, K. W., AND Wilkinson, G. N. 1963. The analysis of adaptation in a plant-breeding programme. Aust. 7. Agric. Res., 14, 742-754.

FREEMAN, G. H. 1973. Statistical methods for the analysis of genotype environment interactions. Heredity, 31, 339-354.

IRGENS-MOLLER, H. 1968. Geographical variation in growth patterns of Douglas-fir. Silvae Genet., 17, 106-110. 
LEvitT, J. 1972. Responses of Plants to Environmental Stresses, 697 pp. Academic Press, New York.

MANDEL, J. 1961. Non-additivity in two-way analysis of variance. F. Am. Stat. Soc. Assoc., $56,878-888$.

MORGENSTERN, E. K., AND TEICH, A. H. 1969. Phenotypic stability of height growth of Jack Pine provenances. Can. 7. Genet. Cytol., 11, 110-117.

PERKINS, J. M., AND JINKS, J. L. 1968. Environmental and genotype-environmental components of variability. III. Multiple lines and cross. Heredity, 23, 339-356.

REHFELDT, G. E. 1974. Local differentiation of populations of Rocky Mountain Douglas-fir. Can. F. For. Res., 4, 399-406.

REHFELDT, G. E. 1978. The genetic structure of a population of Douglas-fir (Pseudotsuga menziesii var. glauca) as reflected by its wind-pollina ted progenies. Silvae Genet., 27, 49-52.

REHFELDT, G. E. 1979a. Genetic differentiation of Douglas-fir populations from the Northern Rocky Mountains. Ecology 59, 1264-1270.

REHFELDT, G. E. 1979b. Patterns of first-year growth in populations of Douglas-fir (Pseudotsuga menziesii var. glauca). USDA For Serv. Res. Note INT-255, 7 pp. Intermt. For. and Range Exp. Stn., Ogden, Utah.

REHFELDT, G. E. 1979c. Variation in cold hardiness among populations of Pseudotsuga menziesii var. glauca. Can. 7. For. Res. USDA For. Serv. Res. Pap. INT -233, 11 pp.

Steel, R. G. D., AND torRIE, J. H. 1960. Principles and Procedures of Statistics, 481 pp. McGraw-Hill, New York.

yates, F., ANd COchran, w. G. 1938. The analyses of groups of experiments. 7. Agric. Sci., $28,556-580$.

WRIGHT, J. W., KUNG, F. H., READ, R. A., LEMMIEN, W. A., AND BRIGHT, J. N. 1971. Genetic variation in Rocky Mountain Douglas-fir. Silvae Genet., 20, 54-60. 